\title{
Rock Mass Characterisation of a Prospective Base Metal Deposit Using a Combined FracMan/ELFEN Approach
}

\author{
N.T. Ford Golder Associates (UK) Ltd, United Kingdom \\ T.R. Silverton Golder Associates (UK) Ltd, United Kingdom \\ M.G. Cottrell Golder Associates (UK) Ltd, United Kingdom
}

\begin{abstract}
This paper demonstrates how the combined use of a discrete fracture network tool (FracMan) and a combined continuum-discrete element tool (ELFEN) has resulted in significant improvements in the understanding of the fundamental mechanisms contributing to rock mass behaviour in poor ground allowing geotechnical risks to be better understood and managed.

The Golder Associates' FracMan combined with Rockfield Software's ELFEN code has been applied to the problem of quantifying the geotechnical risk for a number of potential mining methods being considered for the recovery of a selected lead/zinc ore body in Algeria.

FracMan enables the generation of a rock mass model based on geotechnical data obtained from boreholes, photographs and face mapping. It then permits the creation of integrated three-dimensional (3D) stochastic models using a discrete fracture network (DFN) description. The synthetic fractures in a DFN model can have any size and shape, and can be located deterministically, stochastically, or conditioned to field measurements. The stability of excavations (both 3D benched slopes and complex underground shapes) can be analysed using FracMan. This allows for the identification of completely defined rock blocks formed by finite fractures and allows for the factor of safety of these blocks to be determined in both supported and unsupported ground. The underlying Monte Carlo technique enables sensitivities to ground variability and the quantification of the geotechnical risk for an excavation to be determined.
\end{abstract}

A FracMan model of the selected rock mass from a lead/zinc deposit in poor ground was created using the available geotechnical data. The resulting DFN formed the basis of a series of conceptual models, analysed using the combined continuum-discrete element capabilities of ELFEN. Various potential excavation shapes for underground mining were considered to assess the viability of the mining method and quantify the associated geotechnical risk. ELFEN has been used to examine the fundamental mechanisms contributing to rock fragmentation and the consequent flow of material, this approach enables the rock mass performance to be predicted with confidence.

The use of FracMan modelling and ELFEN to determine the geotechnical risk is a relatively new approach and provides a more powerful tool than traditional methods of rock mass assessment, allowing greater confidence in calculating geotechnical risk during the process of mining method selection and design.

\section{Introduction}

The use of discrete fracture network (DFN) modelling using Golder Associates FracMan geomechanics code and the combination finite element/discrete element code ELFEN made by Rockfield Software is a relatively new development in the field of rock mechanics assessment. The previous use of this method has been applied to mine pillars by Pine et al. (2006) and block cave subsidence by Vyazmensky et al. (2007) and Elmo et al. (2007). This study utilises the technique in order to gain a far greater understanding of the likely performance of an orebody than may be gained by purely empirical methods. In this way it is intended that the risk associated with mining method selection and subsequent design for a prospective base metal mine in poor ground can be lowered. 


\section{$2 \quad$ Numerical modelling}

\subsection{DFN modelling}

\subsubsection{Rationale}

In order to accurately assess the fracture continuity, intensity and potentially unstable fragment size in an underground excavation, an understanding of the 3D geometry of the discontinuities is needed. Since it is impossible to see complete discontinuities present within a rock mass, the two-dimensional (2D) interaction between discontinuities and an exposed surface must be observed and a relationship between the 2D expression and the theoretical 3D fractures must be determined.

DFN modelling allows synthetic, unconditionally simulated fractures to be stochastically generated in 3D. Statistical data is determined from the one-dimensional (1D) and 2D exposures of the fractures and used to build the synthetic model. The mapped and modelled fractures can be compared to validate and, if necessary, refine the model. Several realisations of the model can be run using the Monte Carlo method to gain average values and a measure of the variability present. Once a DFN model has been produced complex excavation shapes may be inserted within the model and the stability of rock fragments within the walls and back of the excavation examined, once again using a Monte Carlo simulation. In this way the geotechnical risk of different excavations maybe characterised.

An important parameter used in the DFN modelling is the fracture intensity, which is described using the volumetric intensity, $\mathrm{P}_{32}$ (total fracture area/unit volume $\left[\mathrm{m}^{2} / \mathrm{m}^{3}\right]$ ). This measure is both scale and directionally independent.

The areal intensity of fracturing, $\mathrm{P}_{21}\left(\mathrm{~m} / \mathrm{m}^{2}\right)$, is defined as the ratio of total length of fracture traces on a surface to the area of that surface. $\mathrm{P}_{21}$ is scale independent, but varies with direction. The modelled $\mathrm{P}_{21}$ can be compared with the mapped $\mathrm{P}_{21}$ from outcrop or excavations. The fracture frequency is described by the $\mathrm{P}_{10}$ (number of fractures per unit length $\left[\mathrm{L}^{-1}\right]$ ) along either a scanline or borehole. The $\mathrm{P}_{21}$ and $\mathrm{P}_{10}$ can be determined for each individual set for all the fractures sets combined.

To conduct the DFN modelling, the FracMan modelling suite by Golder Associates has been used.

\subsubsection{Input}

The inputs required for the DFN modelling are typically (Dershowitz et al., 2004):

- Fracture sets; defined from field observations and stereonet analysis of fracture orientation data.

- Mean fracture orientation and dispersion from stereonet analysis.

- Fracture Spatial model; such as Enhanced Baecher model (Baecher et al., 1977); Levy-Lee Fractal model (Mandelbrot, 1985) or Nearest Neighbour model.

- Fracture intensity; a volumetric intensity value, $\mathrm{P}_{32}\left(\mathrm{~m}^{2} / \mathrm{m}^{3}\right)$ is derived from either mapped areal intensity values, $\mathrm{P}_{21}\left(\mathrm{~m}^{-1}\right)$ or borehole fracture frequency $\left[\mathrm{L}^{-1}\right]$ comparison to the modelled values using a forward modelling method.

- Equivalent fracture radius distribution.

- Fracture shape; usually a polygon equivalent to a circle or possibly elongated in a particular direction.

- Fracture termination; which allows a fracture set to terminate against another earlier fracture set.

DFN models include fractures as planar polygons. This assumption is both realistic and useful, as it allows the approximate representation of a wide variety of fracture shapes by a single mathematical form (Dershowitz et al., 2004). Fracture mechanics suggest that in homogeneous rock the general shape of an isolated fracture should be elliptical, as is assumed in the Baecher model (Baecher et al., 1977). However, as most rock is generally heterogeneous, perfectly elliptical fractures are unlikely to be formed. In a practical sense little error is introduced by representing the ideal, elliptical fracture by a many-sided polygon of 
equivalent area. Dershowitz et al. (2004) has noted, moreover, that observed fractures are generally polygonal due to terminations of the fractures at intersections with other fractures.

To obtain the necessary data for the generation and assessment of DFN models, traditional mapping and logging methods can be used that would be employed for any geotechnical project. Increasingly these methods are supplemented with remote data capture methods.

The fracture orientations, sets and truncation patterns are measured and noted using a combination of direct measurement and observation and any remote imaging data. The intensity of fracturing in 2D is assessed using a combination of mapping and measurements from scaled photographs.

To estimate the equivalent radius distribution of the fractures in the rock mass, the circular window mapping method can be used (Zhang and Einstein, 1998; Zhang and Einstein, 2000; Zhang et al., 2002). In this method the number of continuous and truncated fracture traces are counted within a circle of known radius and used to estimate the true fracture trace length distribution. It is conducted over a wide area on exposures with different orientations and the resulting fracture trace length distribution (in 2D) can be used to estimate the equivalent fracture radius distribution (in 3D). The advantage of circular window mapping is that it removes orientation bias and can be conducted remotely from photos taken of the development or in the field.

\subsubsection{DFN modelling method}

When an initial synthetic fracture set is generated, the volumetric intensity of the fractures, $\mathrm{P}_{32}$, is not known, and an initial estimate is used. To refine the required $\mathrm{P}_{32}$ value, the synthetic fractures must be sampled to determine model values of $\mathrm{P}_{10}$ or $\mathrm{P}_{21}$. These values are then compared with the observed values using Equation (1) to determine an updated value of $\mathrm{P}_{32}$.

$$
P_{32}=P_{10}{ }^{o b s}\left(P_{32}{ }^{\text {Mod/ }} P_{10}{ }^{\text {Mod }}\right)
$$

Where:

Obs $=$ Observed
Mod $=$ Modelled

Once the $\mathrm{P}_{32}$ is updated the model can be re-generated using the new value and sampled once again to check that the model is consistent with the mapped data.

The synthetic fracture sets can be sampled using their intersections with boreholes (or scanlines) in 1D and traceplanes (representing exposed surfaces) in 2D. This data can then be compared to the measured field data to ensure a good match.

Visual comparison of maps and photographs from the field and the traces of the synthetic fractures on traceplanes can be used to check if the synthetic sets appear similar to those mapped in the field. Orientation data can be checked by comparing stereoplots generated from the synthetic fractures with the mapped data. The size and shape of the in situ fragments can be determined by generating an excavation in the DFN model, and then using an algorithm to find whole or nearly-whole blocks created by its intersection with adjacent synthetic fractures.

\subsubsection{Output}

DFN models generate several pieces of data. The DFN models give the $\mathrm{P}_{32}$ volumetric fracture intensity; along with the $\mathrm{P}_{10}$ and $\mathrm{P}_{21}$ for the scan-lines and surfaces in the model. The Monte Carlo fragmentation assessment gives data for average and maximum fragment volume $\left(\mathrm{m}^{3}\right)$ and mass $(\mathrm{t})$ that can be plotted as histograms and cumulative density functions (CDF) that can be considered as size passing curves for the fragmentation. The CDFs may be plotted as classified weight of fragments based on the fragments factor of safety.

\subsubsection{Monte Carlo stability assessment}

The fragmentation stability assessment used in the FracMan Geomechanics capability is based on the program Unwedge developed by Rocscience (Curran, 2006). The method allows for surfaces representing an 
excavation to be inserted into the DFN model and whole fragments defined by the fractures searched for up to a given level of connectivity from the surfaces. The fragments are defined using block theory based on the work of Goodman and Shi (1985) and are formed by the intersection of the fractures and the excavation surface.

Whilst the Unwedge method assumes fractures are persistent, the DFN model uses the more realistic fractures of the DFN itself. The method assumes that stress induced failure does not occur and potential displacement of fragments is assumed to take place on the fractures which define the fragment, and that the fragments are rigid bodies which suffer no internal deformation or cracking. All of the discontinuity surfaces are assumed to be perfectly planar. The analysis is based upon the assumption that the wedges are subjected to gravitational loading based only on the rock density value used, i.e. the stress field in the rock mass surrounding the excavation is not taken into account. The FracMan inputs required for the fragmentation assessment are shown below:

- Slope or tunnel surface.

- Connectivity level of fractures from surface.

- Rock density.

- Seismic acceleration.

- Water pressure (phreatic surface or constant).

- Fracture properties (Mohr-Coulomb or Barton Bandis).

- Friction angle.

- Support patterns.

The density is used in calculation of the weight of a fragment to see if it is kinematically stable under the influence of all driving and resisting forces. However, if there is a large percentage of the fragments appearing as unstable then the rock mass may be predicted to cave preferentially.

The seismic acceleration is a pseudo-static force applied to the rock mass in order to simulate seismic activity. Water pressure can be included into the DFN model either as a phreatic surface or as constant pressure with a particular direction. Application of water pressure will decrease the effective normal stress on the fractures making any fragment defined less stable. The fragmentation assessment allows for the fracture properties to be set. For the study presented, the Mohr-Coulomb failure criterion has been used with cohesion, $c$, and the friction angle $\phi$.

The fracture cohesion $\left(\mathrm{N} / \mathrm{m}^{2}\right)$ is a term used for convenience and refers to a mathematical quantity related to surface roughness (Hoek 2000) and the true fracture cohesion refers to the cemented surfaces that are being sheared (Chitombo, 2005). The basic angle of friction $\phi_{\mathrm{b}}$ can be measured in a laboratory is approximately equal to the residual friction angle $\phi_{\mathrm{r}}$ (Hoek 2000). Once the basic friction angle is determined a correction for surface roughness can be made to give an effective friction angle. The fragmentation assessment allows the implementation of support patterns using up to two rock bolting patterns.

\subsection{ELFEN}

Complimenting the use of the FracMan DFN code to investigate the stability of open stopes in the selected lead/zinc deposit, the numerical code ELFEN by Rockfield (2008) has been used to investigate the caveability of sublevel cave panels. A 2D ELFEN model based on an east-west orientated slice through the DFN was generated and representative panels of material were then removed from the model and the overlying material allowed to cave.

\subsubsection{Rationale}

The ELFEN approach is founded upon the use of a combined finite and discrete element technique. The use of such a technique permits the two key mechanical processes of rock fragmentation and fragment 
interaction to be physically simulated and, more importantly, understood. Within this strategy there are a number of key features that ultimately drive the approach forward, these are:

- Appropriate element modelling of the continuum and discrete regions.

- Explicit time integration using the central difference method.

- An advanced nonlinear and pressure sensitive material description.

- Automatic fracture insertion strategies based on the evolving response.

- Automatic monitoring of the interaction of discrete bodies, and physically representative frictional and compliant behaviour of bodies.

The bulleted items above provide an indication of the core components within the ELFEN framework. For further detailed information relating to these, the interested reader is referred to the research work of $\mathrm{Yu}$ (1999), Klerck (2000), and Cottrell (2002), with the more recent application-based articles by Klerck et al. (2004), Owen et al. (2004) and Rance et al. (2007).

\subsubsection{Input}

The inputs required for the ELFEN modelling in terms of modelling underground mining operations are typically aimed at being as representative of the physical processes as possible. Within the current modelling, the first target is establishing the fundamental geometry of the problem, specifically taking representative jointing sets obtained from the DFN model and manipulating them in order to form an accurate yet efficient finite and discrete element model. Efficiency in terms of finite and discrete element modelling considered ultimately means that poorly conditioned elements that have implications to the time step length are removed from the model system.

In addition to the geometric requirement of the model, it is necessary to ensure that the material representations employed are appropriate. In the case of pressure dependent materials such as rocks and soils, this ultimately means using the compressive fracture model developed by Klerck (2000) and rigorously used in the recent works of Rance et al. (2007) and Elmo et al. (2007). The use of the compressive fracture model enables the continuous finite element description to transform seamlessly via a strength criterion to an assemblage of discrete blocks when under the action of mechanical deformation (Yu, 1999; Cottrell, 2002). In addition to providing descriptions for the intact material behaviour of rocks and soils, the approach also provides a set of interaction models to allow specification of nonlinear frictional and compliance type models.

\subsubsection{Output}

As with virtually all numerical techniques, there is a significant amount of data generated from ELFEN during the course of an engineering analysis. In terms of the current mine study, a number of measures which contribute to the understanding the rock mass behaviour are studied. The principal output from the ELFEN modelling is to provide an indication of the success likely to be achieved for a small number of different mining methods. This is achieved primarily through examination of the fragmentation levels achieved during the mining process, in addition, the fragmentation levels are further supported through examination of the principal modelling variables of displacement and stress.

\section{Selected lead/zinc deposit}

\subsection{Background}

The selected lead/zinc deposit is located in the Atlas Mountains in the north of Algeria, $270 \mathrm{~km}$ east of Algiers and $10 \mathrm{~km}$ south of the city of Bejaia. The mountain region has elevations up to $730 \mathrm{~m}$ above sea level and is cut by steep valleys. 


\subsection{Geology}

The ore-containing massif is of Miocene age and covers an area of $105 \mathrm{~km}^{2}$. The massif belongs to the Rifan and Tellian chains of the Atlas Mountains that stretch along the western Mediterranean Sea.

In the area of the selected lead/zinc deposit, two volcanic masses can be distinguished. The $600 \mathrm{~m}$ thick Lower Volcanic Series comprised of lavas, tuffs and andesitic breccias and the $300 \mathrm{~m}$ thick Upper Volcanic Series comprised of lavas, tuffs and dacitic breccias. Sub-volcanic bodies crosscut both masses with the main one being a rhyolitic sill in the middle part of the lower mass with which the mineralisation is spatially related.

The southern low-grade zone of the selected lead/zinc deposit is located in a downthrown block and the northern high-grade in an up thrown block of the Nait-Larbi fault. In the vicinity of the fault, rocks are deeply altered. The Nait-Larbi fault was active during the Miocene period of time.

The mineralisation is controlled by the Nait-Larbi fault and is hosted in the andesitic lavas underlying the rhyolitic sill. Highgrade ore is associated with strong hydrothermal alteration characterised by pyritisation, silicification, chloritisation, sericitisation, carbonatisation and kaolinitisation. The deposit is stratiform, dipping to the north and south and lies at a depth of $270-550 \mathrm{~m}$. The mineralisation occurs as either brecciated impregnation or stockworks and the main ore consists of pyrite, sphalerite and galena. Within the main selected lead/zinc orebody, the mineralisation can be found as:

- Massive intervals from five $\mathrm{cm}$ to five to six metres thick.

- Semi-massive intervals.

- In veins and veinlets disseminated within altered pyroclastics.

Massive mineralisation is found preferentially within the fine-grained porphyroclastics whilst the semimassive to disseminated mineralisation is found within the andesitic lavas of the Lower Volcanic series. Veins and disseminated mineralisation are found throughout the deposit, associated with strong alteration of the volcanics and intrusive.

\subsection{Geotechnical conditions}

From a combination of mapping at the drill site and two sections of orientated core, three fracture sets were determined (Figure 1). The orientation and distribution of these fracture sets was then used as a basis for input into the DFN model. The key $\mathrm{P}_{21}$ values were determined from face mapping of outcrops at the deposit drill site for each fracture set, based primarily on cuttings striking $120^{\circ}$ and $100^{\circ}$. Complementing this a phase of circular window mapping was used to estimate the mean fracture trace length and the corresponding coefficient of variance. These values were then used to determine the equivalent fracture radius, of which details are given in Table 1.

\section{Modelling results}

\subsection{Sublevel open stope stability using the FracMan DFN approach}

\subsubsection{Data and method}

The mapped fracture data was used to create the DFN model based on the technique described previously. The values used are given in Table 3. A 1,000,000 $\mathrm{m}^{3}$ cube was used as the outer bounding box. Two planes of $1000 \mathrm{~m}^{2}$ striking at $100^{\circ}$ and $120^{\circ}$ were inserted and used to examine the $\mathrm{P}_{21}$ values for the model using the method described previously. 

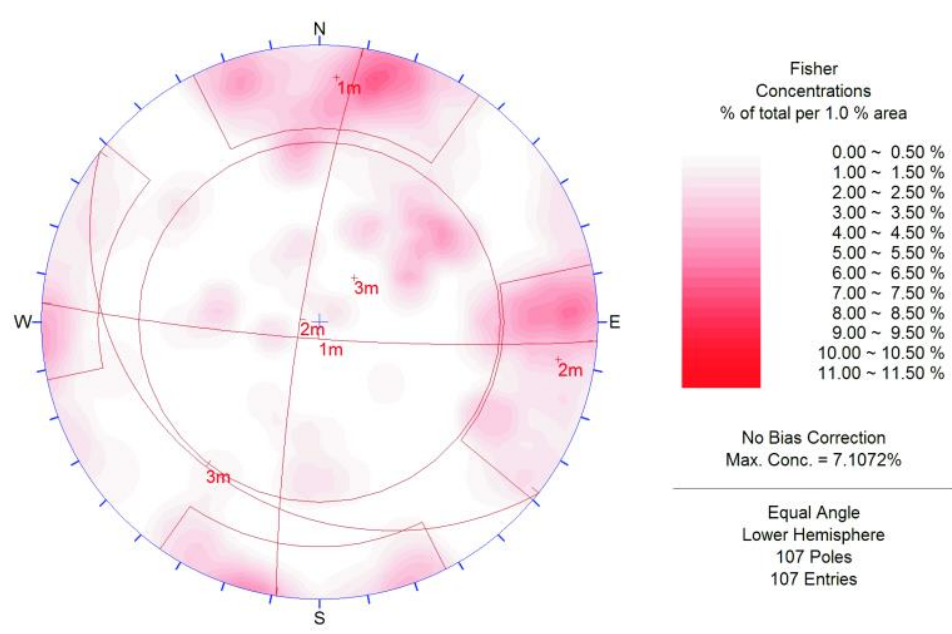

No Bias Correction

Max. Conc. $=7.1072 \%$

Equal Angle

Lower Hemispher

107 Entries

Figure 1 Stereonet of mapping from selected lead/zinc drill site

Table 1 Fracture set data from the selected lead/zinc deposit site

\begin{tabular}{ccccccc}
\hline \multicolumn{7}{c}{ Equivalent Fracture Radius } \\
\hline Set & Dip & Dip Direction & Kappa & $\mathrm{P}_{32}\left(\mathrm{~m}^{2} / \mathrm{m}^{3}\right)$ & $\mu_{\mathrm{D}}(\mathrm{m})$ & $\sigma_{\mathrm{D}}$ \\
\hline 1 & $83.1^{\circ}$ & $184.4^{\circ}$ & 18.4 & 1.23 & 0.9 & 0.5 \\
2 & $81.7^{\circ}$ & $278.9^{\circ}$ & 21.7 & 0.76 & 0.6 & 0.6 \\
3 & $22.5^{\circ}$ & $217.6^{\circ}$ & 3.4 & 1.28 & 0.9 & 0.6 \\
\hline
\end{tabular}

Previous work at the selected lead/zinc deposit site had determined that open stopes $20 \mathrm{~m}$ high by $15 \mathrm{~m}$ long and seven metres wide were proposed based on the Extended Mathews Stability Method (Mathews et al., 1980; Trueman et al., 2000). Four open stopes were inserted with the above dimensions within the DFN model. The first two stopes with their long axis east-west were set to dip towards $0^{\circ}$ and $180^{\circ}$ at $80^{\circ}$ and two further stopes with their longest axis running north-south were set to dip at $80^{\circ}$ towards $90^{\circ}$ and $270^{\circ}$.

A rock wedge analysis was then conducted. The rock wedge analysis is based on the Rocscience's Unwedge engine (Collins, 2004). No water or rock bolt support was used in the model. The Mohr-Coulomb values for the fractures was set with no cohesion and a friction angle of $26.5^{\circ}$ and the rock mass bulk density was set at $2700 \mathrm{~kg} / \mathrm{m}^{3}$.

The rock wedge analysis was then run using a Monte Carlo simulation method with 10 realisations for each stope. The DFN was regenerated for each realisation of the model. Figure 2 shows a realisation of the DFN with $50 \%$ of the fractures show in a $125,000 \mathrm{~m}^{3}$ box.

\subsubsection{Results}

The results of the DFN stability analysis show that unstable fragments form around the excavation for all of the stope orientations. The majority of fragments within the DFN are small, typically less then $1 \mathrm{~m}^{3}$ in volume. In Figure 3 the fragments around the open stope design are presented, the black fragments indicate kinematical instability whilst grey fragments are considered totally stable.

In addition, Figure 4 demonstrates the CDF of the composite fragments volume showing the similarity in fragment size distribution around between the different stope orientations. 


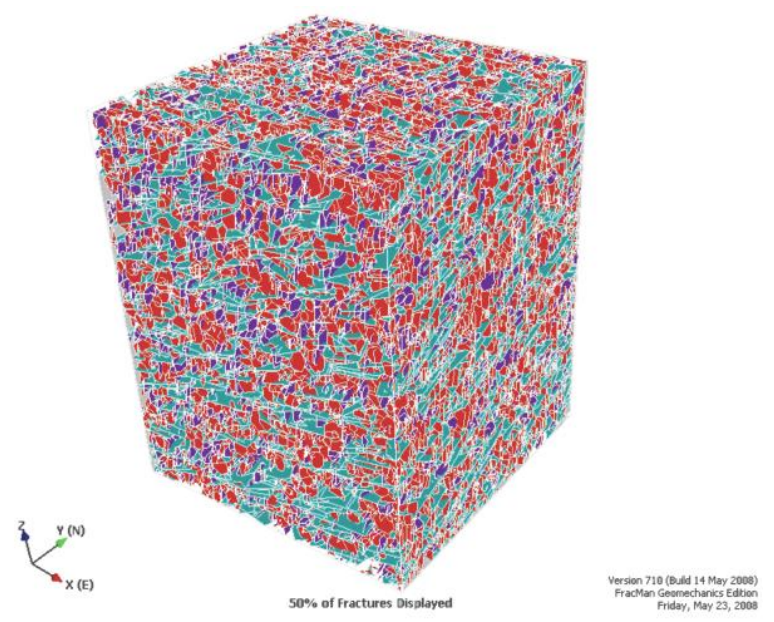

Figure 2 A $50 \times 50 \times 50 \mathrm{~m}$ box containing one realisation of the DFN with $50 \%$ of fractures visible

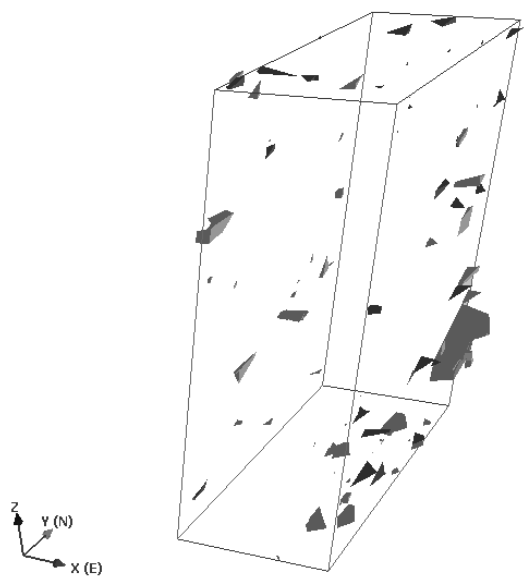

Figure 3 Fragments formed within one realisation of the DFN around an open stope design; black fragments are kinematically unstable and the grey fragments are stable 


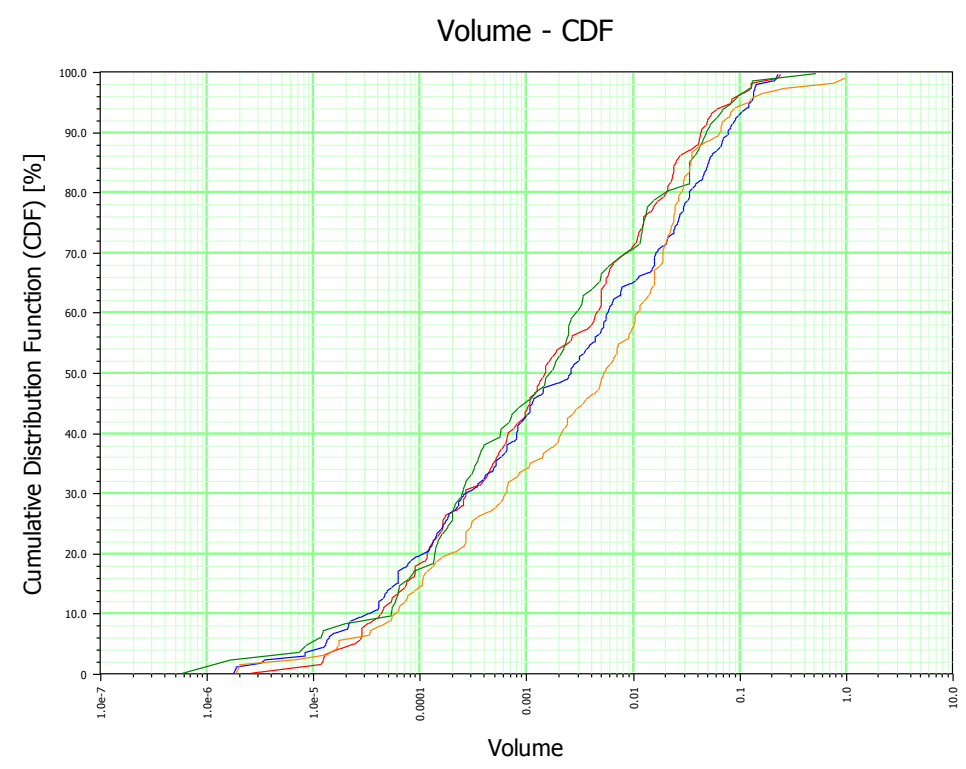

Figure 4 CDF of composite fragment volume $\left(\mathrm{m}^{3}\right)$ for various dip directions

\subsection{Sublevel cave analysis using ELFEN}

\subsubsection{Data and method}

\subsubsection{Geometry input}

From the FracMan model an east-west section has been created along the centre line of the DFN model region. It has then been possible to export fracture traces from each of the three fracture sets from the DFN model. The three fracture set traces imported into ELFEN are shown in Figure 5.

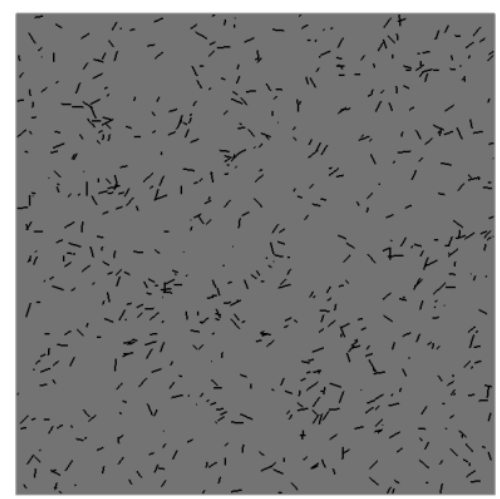

(a) Set 1

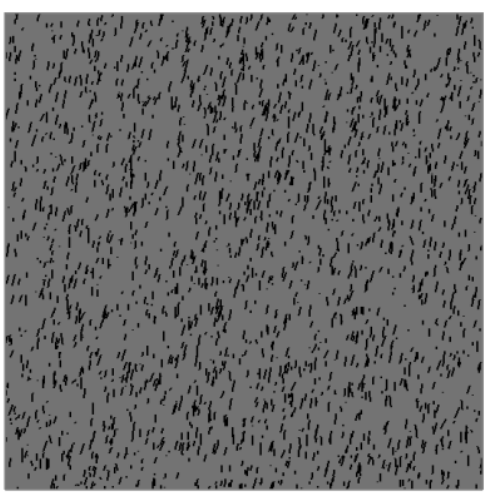

(a) Set 2

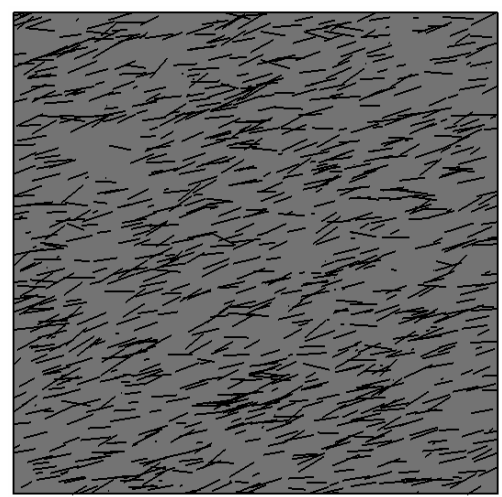

(a) Set 3

Figure 5 Summary of the individual FracMan jointing profiles imported into ELFEN

Upon import of the three fracture sets it was necessary to perform some assessment and manipulation of the raw joint data. This operation is necessary in order to remove any unessential or inefficient detail from the model. Typically, the types of detail removed from the model include very short isolated joints and exceptionally close parallel joints. The removal of such fine detail from the model has been shown in previous investigations (Rance et al., 2007) not to alter the global behaviour of the modelling system.

The approach employed for the transfer of the raw DFN data to the ELFEN model is included in the following steps: 
- The raw traceplane data is exported from the DFN model via ASCII files. The traceplane information is imported into ELFEN in which the joints are represented as 2D segmented lines.

- Each fracture line is then assigned interface properties such as friction coefficient, cohesion, shear and normal stiffness.

- Fracture entities are first constructed independently as a network, accounting for intersections of lines or surfaces, including the partial intersection with material region boundaries.

- Once the network has been constructed these are embedded within a solid model of the rock mass.

- This solid model is then discretised to provide an unstructured triangular finite element mesh using automatic mesh generation techniques. During this operation additional operations are performed to ensure that neither excessively small nor sliver elements are generated.

Within Figure 6(a) the jointing profile after the removal of the superfluous short and close parallel entities is presented, in addition Figure 6(b) presents the employed finite element mesh used for the analyses.

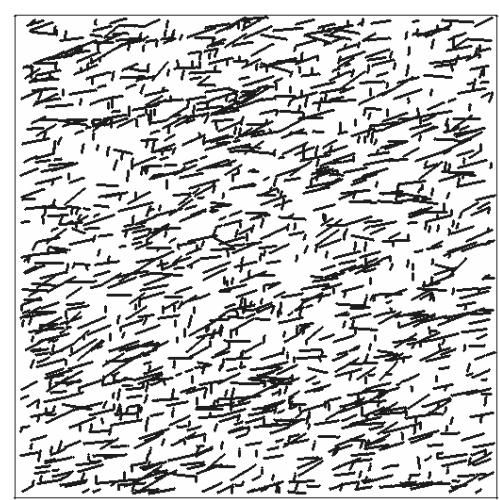

(a)

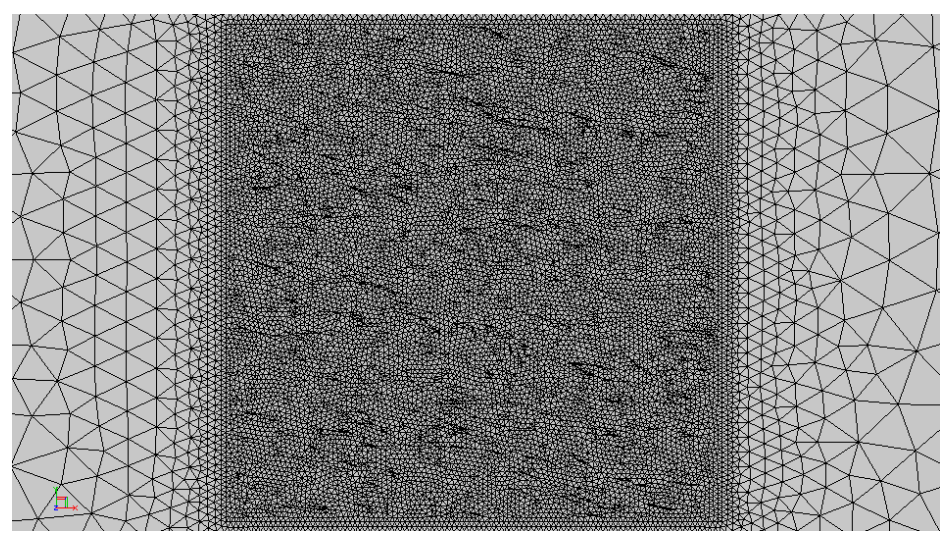

(b)

\section{Figure 6 (a) ELFEN jointing profile; (b) ELFEN initial finite element mesh}

\subsubsection{Material property data}

The material data employed has been generated based largely on a suite of laboratory tests considering the basic physical properties and using some on site observations. Using this data as input for RocLab (Hoek et al., 2002) a material strength envelope has been defined which is directly compatible to the ELFEN compressive fracture and discrete element joint interface models, this data is presented in Tables 2 and 3.

\subsubsection{Results}

In performing these types of ELFEN simulations it is well established that the setting up of the initial conditions can be very time consuming with much numerical iteration required to provide a balance of reduced dynamic influence against computational efficiency. Within the current strategy a geostatic stress approach has been employed such that the in situ stress levels in the vertical and lateral directions are instantaneously established. The ratio between the vertical and lateral stresses is specified in the standard geotechnical manner of using a $\mathrm{K}$ ratio. Using such an approach the initial stress conditions are achieved in one numerical time step and as a consequence have zero displacement, however due to the nature of the discrete fracture network the in situ stress levels are transferred to the DE fractures such that contact can be effectively realised. In Figure 7 the establishment of the vertical geostatic stress conditions for the global model and the highly refined discretely fractured model is presented. 
Table 2 Summary of intact material properties

\begin{tabular}{lc}
\hline Material Property & Value \\
\hline Elastic modulus $(\mathrm{E})(\mathrm{MPa})$ & 60,000 \\
Poisson ratio $(v)(-)$ & 0.23 \\
Bulk density $(\rho)\left(\mathrm{kg} / \mathrm{m}^{3}\right)$ & 2700 \\
Mohr-Coulomb cohesion $(\mathrm{Coh})(\mathrm{MPa})$ & 25 \\
Mohr-Coulomb friction angle $(\mathrm{phi})($ degrees$)$ & 43 \\
Tensile strength $\left(\mathrm{f}_{\mathrm{t}}\right)(\mathrm{MPa})$ & 4.5 \\
Specific fracture energy $\left(\mathrm{G}_{\mathrm{f}}\right)\left(\mathrm{J} / \mathrm{m}^{2}\right)$ & 60 \\
\hline
\end{tabular}

Table 3 Summary of joint properties

\begin{tabular}{lc}
\hline Frictional Property & Value \\
\hline Coulomb friction coefficient $(\mu)(-)$ & 0.75 \\
Cohesion coefficient $(\mathrm{C})(\mathrm{MPa})$ & 0.00 \\
\hline
\end{tabular}

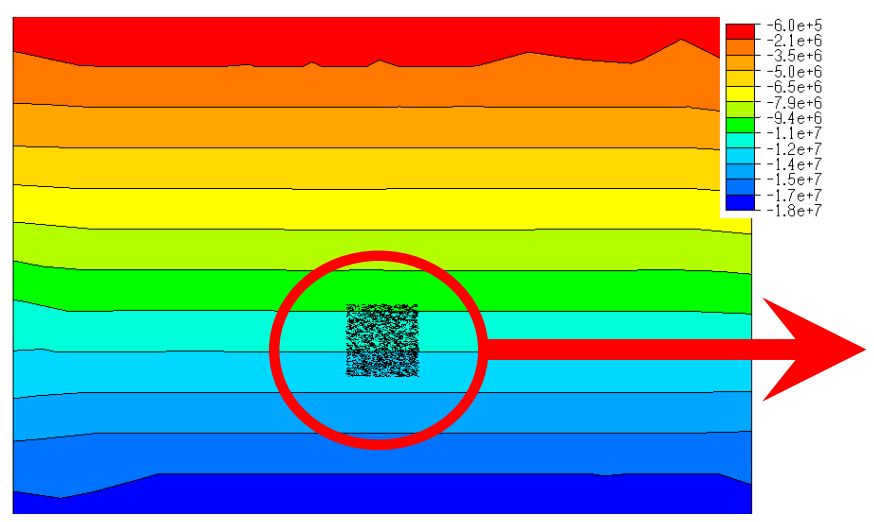

(a) Global in situ stress profile

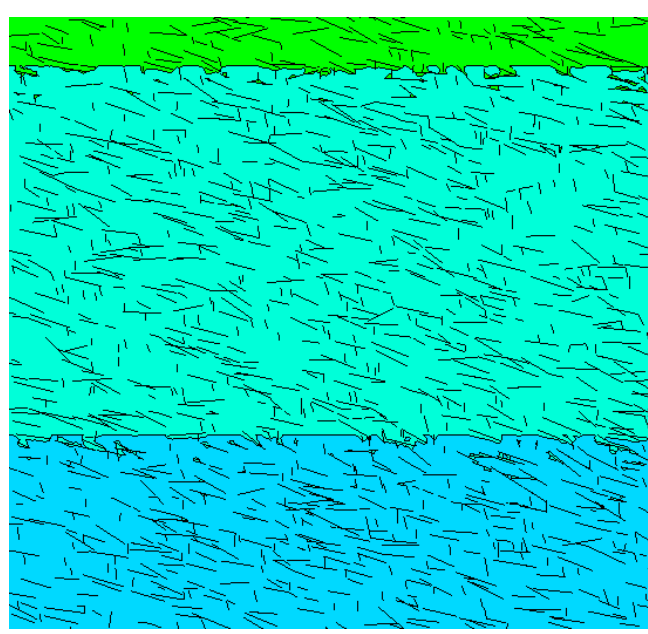

(a) Local mine region in situ stress profile

Figure 7 Establishment of the model geostatic stress conditions showing (a) the global vertical stress profile; (b) the vertical stress profile in the discretely jointed region 


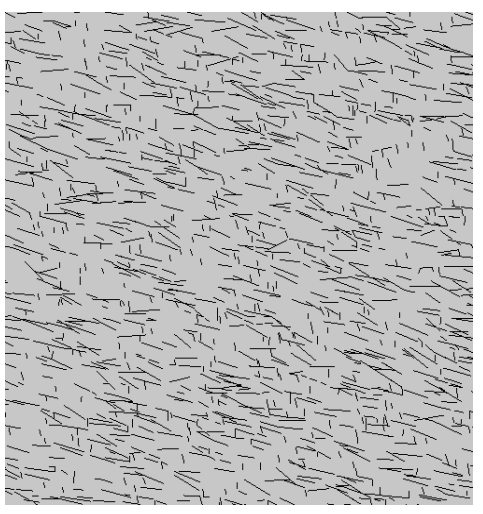

(a) initial fracture model

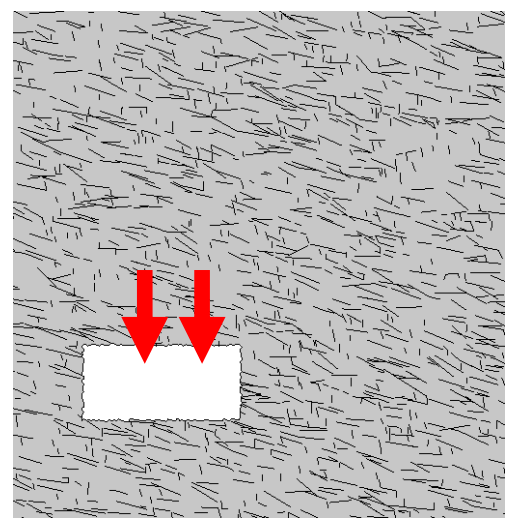

(d) sublevel panel 3

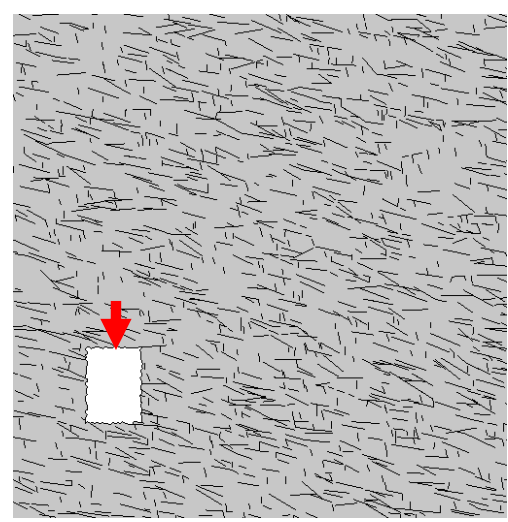

(b) sublevel panel 1

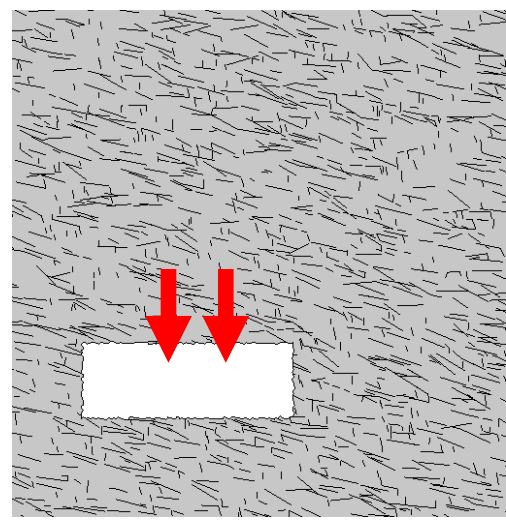

(e) sublevel panel 4

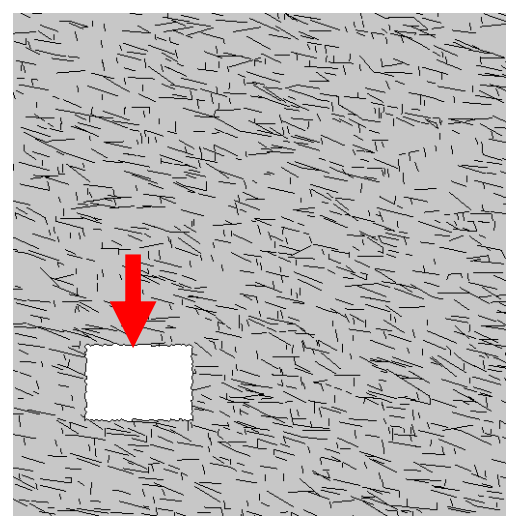

(c) sublevel panel 2

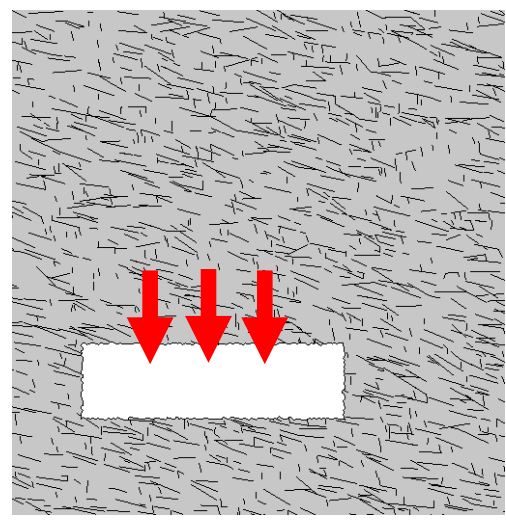

(f) sublevel panel 5

\section{Figure 8 Evolution of the mining sequences employed within the ELFEN model. Arrows showing expected fragment failure}

In Figure 8 the development of the panel caving model is presented. Within this model discrete sections of material are removed during the analysis. Ongoing investigations are assessing how the removal of material from the model affects the support of the roof material, and assessments are being performed to relate the displacement and fracture evolution to the purpose of mining method selection.

\section{Conclusions}

The combination of FracMan DFN modelling and numerical modelling using ELFEN is a promising method for the future design and assessment of metal mines in poor ground. Further investigative modelling work is required based on more detailed data still to be collected during the phase of the mine designs.

The combination of the DFN and ELFEN modelling techniques allows for the performance of the models to be calibrated against previous real life examples by varying the parameters used in the model and comparing the results with real life performance. This calibration allows for a level of inherent confidence within the model results and hence in the geotechnical risks involved in the mining method.

At present the use of numerical modelling can only be used to support the traditional empirical methods of mine design. This is due to the relatively few case examples (compared to empirical methods) available for calibration and the specialist nature of the modelling. Eventually, as modelling becomes more advanced and more case studies become available, this may change. However, this approach allows for a much greater understanding of the processes and risks involved than would be available with a purely empirical approach. 


\section{References}

Baecher, G.B., Einstein, H.H. and Lanney, N.A. (1977) Statistical description of rock properties and sampling. Proceedings 18th U.S. Symposium on Rock Mechanics, Barton, C.M., Colorado School of Mines Press Colorado, pp. 1-8.

Chitombo, G. (2005) The International Caving Study (ICS) End of project report. ICS II. JKMRC, The University of Brisbane, Queensland, Australia.

Collins, T. (2004) Image J: Image Processing and Analysis In Java. Toronto: Wright Cell Imaging Facility, Toronto Western Research Institute.

Cottrell, M.G. (2002) Rational Computational Strategies for Modelling High Velocity Impact, PhD thesis, University of Wales Swansea.

Curran, J. (2006) Unwedge v.3.0 Tutorial Manual. Rocscience.

Dershowitz, W., Lee, G., Geier, J., Foxford, T., LaPointe, P. and Thomas, A. (2004) Fracman, Interactive Discrete Feature Data Analysis, Geometric Modelling, and Exploration Simulation, User Documentation, Golder Associates Inc, $231 \mathrm{p}$.

Elmo, D., Vyazmensky, A., Stead, D. and Rance, J.R. (2007) A Hybrid FEM/DEM Approach To Model The Interaction Between Open Pit And Underground Block Caving Mining. Proceedings 1st Canada-U.S. Rock Mechanics Symposium. Vancouver B.C. 27-31 May 2007.

Goodman, R. and Shi, G. (1985) Block Theory and Its Application to Rock Engineering, Prentice-Hall, London.

Hoek, E. (2000) Practical Rock Engineering. Rocscience.

Hoek, E., Carranza, T.C. and Corkum, B. (2002) Hoek-Brown Failure Criterion - 2002 Edition. Proceedings of the Fifth North American Rock Mechanics Symposium, Toronto, Canada Vol. 1, pp. 267-273.

Klerck, P.A. (2000) The finite element modelling of discrete fracture in quasi brittle materials. PhD thesis, University of Wales Swansea.

Klerck, P.A., Sellers, E.J. and Owen, D.R.J. (2004) Discrete fracture in quasi brittle materials under compressive and tensile stress states, Computer Methods in Applied Mechanics in Engineering, Vol. 193, pp. 3035-3056.

Mandelbrot, B.B. (1985) Self-Affine Fractals and Fractal Dimension, Physica Scripta, 32 p, pp. $257-260$.

Mathews, K.E., Hoek, E., Wyllie, D.C. and Steward, S.B.V. (1980) Prediction of Stable Excavations for Mining at Depths Below 1000 Metres in Hard Rock. CANMET 802-1571.

Owen, D.R.J., Feng, Y.T., de Souza Neto, E.A., Cottrell, M.G., Wang, F., Pires, F.M. and Yu, J. (2004) The Modelling Of Multi-Fracturing Solids And Particulate Media, International Journal of Numerical Methods in Engineering, Vol. 60, pp. 317-339.

Pine, R.J., Coggan, J.S., Flynn, Z. and Elmo, D. (2006) The Development of A Comprehensive Numerical Modelling Approach For Pre-Fractured Rock Masses. Rock Mechanics and Rock Engineering, 39, 5, pp. 395-419.

Rance, J.M., Van As, A., Owen, D.R.J., Feng, Y.T. and Pine, R.J. (2007) Computational Modelling Of Multiple Fragmentation In Rock Masses With Application To Block Caving. Proceedings 1st Canada-US Rock Mechanics Symposium, Vancouver, Canada.

Rockfield (2008) ELFEN Finite Element/Discrete Element code. Rockfield Software Ltd, Swansea.

Trueman, R., Mikula, P., Mawdesley, C. and Harries, N. (2000) Experience In Australia With The Application Of The Mathews' Method For Open Stope Design, Canadian Institute of Mining Bulletin 93, pp. 162-167.

Vyazmensky, A., Elmo, D., Stead, D. and Rance, J.R. (2007) Combined Finite-Discrete Element Modelling Of Surface Subsidence Associated With Block Caving Mining. Proceedings 1st Canada-U.S. Rock Mechanics Symposium. Vancouver, Vol. 1, pp. 467-475.

Yu, J. (1999) A contact interaction framework for numerical simulation of multi-body problems and aspects of damage and fracture for brittle materials. PhD thesis, University of Wales Swansea.

Zhang, L. and Einstein, H.H. (1998) Estimating The Mean Trace Length Of Rock Discontinuities. Rock Mechanics and Rock Engineering, 4, Springer, pp. 217-235.

Zhang, L. and Einstein, H.H. (2000) Estimating the Intensity of Rock Discontinuities. International Journal of Rock Mechanics and Mining Science, 37, Elsevier, pp. 819-837.

Zhang, L., Einstein, H.H. and Dershowitz, W.S. (2002) Stereological Relationship Between Trace Length And Size Distribution Of Elliptical Discontinuities. Géotechnique, 52, Institute of Civil Engineers, pp. 419-433. 
